\title{
Percepções do uso de Ferramentas Online no processo de Ensino-Aprendizagem de Física para o Ensino Médio em Escolas Públicas do Sudoeste do Paraná
}

\author{
Rosaine Fiorio $^{1}$, Paulo Junior Varela ${ }^{1}$, Jhonnatan Ricardo Semler ${ }^{1}$ \\ ${ }^{1}$ Grupo de Pesquisa Intelagir - Licenciatura em Informática - Universidade Tecnológica Federal do Paraná (UTFPR) \\ Caixa Postal 135 - 85.601-970 - Francisco Beltrão - PR - Brazil \\ \{rosainefiorio\}@gmail.com, \{paulovarela,jrsemler\}@utfpr.edu.br
}

\begin{abstract}
This article presents perceptions of the use of online tools in the teaching-learning process of contents of the subject of Physics in Public Schools in the Municipality of Francisco Beltrão, state of Paraná. In this context, a survey was carried out with 343 students from 22 high school classes. During the teaching-learning of contents, the Khan Academy tool was used to assist in the process, to observe the evolution of learning and the acceptance of technological tools by the student. At this point, it was found that more than $90 \%$ of students felt more interested in the class, due to the fact that the tool has multimedia and dynamic content.
\end{abstract}

Resumo. Este artigo apresenta percepções do uso de ferramentas online no processo de ensino-aprendizagem de conteúdos da disciplina de Física em Escolas Públicas do Município de Francisco Beltrão, estado do Paraná. Neste contexto, foi realizada uma pesquisa com 343 alunos de 22 turmas do ensino médio. Durante o ensino-aprendizado de conteúdos foi utilizada a ferramenta Khan Academy como auxiliar no processo, para observações da evolução do aprendizado e da aceitação de ferramentas tecnológicas pelo aluno. Neste ponto, verificou-se que mais de $90 \%$ dos alunos se sentiram mais interessados na aula, pelo fato da ferramenta apresentar conteúdos multimídia e dinâmicos.

\section{Introdução}

As ferramentas de tecnologia da informação, à certo tempo, estão sendo incorporadas ao contexto escolar como auxiliar no processo de ensino e aprendizagem, que transpassa a barreira multidisciplinar, pois pode permear diferentes assuntos [An et al., 2013]. Neste contexto, diversos são os exemplos que estão obtendo sucesso no ambiente de ensino-aprendizagem, tais como: (i) jogos educativos para auxiliar o processo de alfabetização [An et al., 2013][Neto et al., 2013]; (ii) ambientes virtuais para apoiar o ensino e a aprendizagem [Torezani et al., 2013]; (iii) utilização de recursos da robótica educacional [Trentin et al., 2013] [Fiorio et al., 2014]; (iv) recursos de dispositivos móveis para apoiar a aprendizagem colaborativa [Luz e Fonseca, 2013]; e, (v) softwares de auxilio no processo de aprendizagem [Fiorio et al.,2019].

Percebe-se, que de maneira geral, as aulas ministradas nas escolas públicas, são caracterizadas pela transmissão de conhecimentos e conteúdos do professor para o aluno no formato tradicional, ou seja, o professor verbaliza as explicações dos conceitos abordados pelo livro didático, resolve e propõe exercícios e, em poucos momentos (devido a indisponibilidade de material ou laboratório) realiza experimentos e/ou apresentações para ilustrar a teoria [Trentin et al., 2013]. Observa-se que o contexto da tecnologia e seus novos princípios não tenham significado o fim do modelo tradicional de ensino. No entanto, ainda são necessárias diversas ações para tornar conhecidas, disponíveis e usuais diversas iniciativas que auxiliam professores e alunos no processo de ensino-aprendizagem. E, neste caso, o uso de plataformas online de conteúdo podem ser uma alternativa para aproximar professores e alunos das tecnologias aplicadas ao ensino.

A literatura tem apontando para a importância da relação professor-aluno, de maneira que alguns autores propõe que o professor seja o sujeito responsável pela introdução do aprendiz no conceito cultural, mediando as ideias e concepções e o saber 
formal, donde o aluno ocupa uma posição mais ativa no processo ensino-aprendizagem [Mortimer e Scott 2002] [Orsolini, 2005] [Monteiro et al., 2007] [Bozelli e Nardi, 2012] [Nascimento et al.,2015]. O uso de tecnologias voltadas para a educação trazem inúmeras possibilidades para a educação, visto que a tecnologia, quando em ambiente educacional, pode auxiliar os estudantes no processo ensino-aprendizagem para que se tornem: (i) tomadores de decisões e solucionadores de problemas; (ii) comunicadores e colaboradores criativos; (iii) pessoas que buscam, analisam e avaliam a informação; e, (iv) cidadãos informados, criativos, responsáveis, qualificados e que levem contribuições à sociedade.

Nas últimas décadas a tecnologia se inseriu na paisagem educacional possibilitando a abertura para novas perspectivas de desenvolvimento educacional. As tecnologias educacionais que mais ganharam notoriedade foram as que permitem alternar entre sessões de ensino online com aulas presenciais. Dentre essas ferramentas, a plataforma online de ensino Khan Academy tem obtido destaque.

Esse trabalho aborda a aplicação da plataforma Khan Academy como auxiliar no processo de ensino-aprendizagem de conteúdos da disciplina de Física para o ensino médio. Justificamos a escolha da plataforma, pelo fato de que no contexto educacional, possibilita a incorporação de diferentes mídias como vídeos, e-books, bibliotecas virtuais, resolução de atividades, entre outros recursos. Além do mais, o uso de plataformas online de estudos é uma abordagem de iniciação ao uso de tecnologias educacionais, não necessitando por parte dos professores e alunos conhecimento aprofundados na área tecnológica. A aplicação se deu em 22 turmas do ensino médio pertencente à escolas da rede pública de ensino do Sudoeste do Paraná.

Este artigo está estruturado da seguinte forma: A seção 1 apresenta a introdução. A parte 2 descreve a fundamentação teórica. A parte 3 apresenta os materiais e métodos. Os resultados e a discussão são apresentados na parte 4. E, na parte 5 são apresentadas as conclusões e trabalhos futuros.

\section{Fundamentação Teórica}

\subsection{Ensino Aprendizagem com Tecnologia em Física}

Para [Araujo, 2006], existem diferentes propostas didáticas para o uso do computador no ensino da Física, dentre os quais pode-se destacar: tutoriais, softwares de aquisição de dados, simulação, modelagem e o m-learning.

De acordo com [Andrade, 2015] e [Fiorio et al., 2019], a partir do advento da internet e das tecnologias de conexão sem fio (wireless), tornou-se possível o desenvolvimento de ambientes de aprendizagem. Neste caso, pode-se disponibilizar para acesso dos alunos: animações, simulações, vídeos, entre outros recursos. Neste contexto, surgiu o conceito de mobile learning (m-learning). Este conceito pode ser definido como o processo de ensino e aprendizagem integrado com as tecnologias de informação e comunicação móveis, possibilitando ao aluno oportunidade de aprendizagem mesmo em distâncias físicas e/ou geográficas em outros momentos intransponíveis [Batista et al., 2012].

$\mathrm{Na}$ literatura, observa-se que há poucos estudos e relatos da aplicação de ferramentas e/ou plataformas ligadas as tecnologias da informação e comunicação no ensino da Física. Os trabalhos elencados na Tabela 1 podem ser classificados em três grandes 
categorias: $(i)$ princípios e ideias gerais sobre a possibilidade de uso das tecnologias da informação e comunicação no ensino de Física; (ii) o uso de software e seu entorno docente; (iii) análise do uso de tecnologias como simulação e modelagem. Percebe-se, que nenhum dos trabalhos dá ênfase à aplicação de ferramentas tecnológicas que possam disponibilizar conteúdos e atividades à distância. Na maioria dos trabalhos, é relatado que quando são utilizadas ferramentas computacionais para auxiliar no processo ensino aprendizagem, há melhora significativa na aprendizagem dos alunos.

Este trabalho, atua no sentido de preencher esta lacuna, discutindo a aplicação de ferramentas de educação à distância com conceitos lúdicos e criativos na interação com o aluno no processo de ensino aprendizagem do aluno.

Tabela 1. Aplicação de Ferramentas da Tecnologia da Informação na Educação

\begin{tabular}{|c|c|l|}
\hline Autores / Ano & Tecnologia & \multicolumn{1}{|c|}{ Resultados } \\
\hline Andrade [2015] & $\begin{array}{c}\text { Uso de Software para } \\
\text { modelagem }\end{array}$ & $\begin{array}{l}\text { Aprendizado mais eficaz, visto que a interação dos alunos com o objeto de } \\
\text { estudo e com as ferramentas educacionais é muito maior quando comparado } \\
\text { com as metodologias tradicionais. }\end{array}$ \\
\hline $\begin{array}{c}\text { Bozelli e Nardi } \\
{[2012]}\end{array}$ & $\begin{array}{c}\text { Processo Interativos e } \\
\text { Discursivos (Analogias) }\end{array}$ & $\begin{array}{l}\text { Maiores discussões sobre o uso de analogias no ensino, na formação inicial } \\
\text { dos professores, sua função, vantagens e desvantagens. }\end{array}$ \\
\hline $\begin{array}{c}\text { Gonçalves [2005] } \\
\text { extras (multimídia) }\end{array}$ & $\begin{array}{l}\text { Melhorias significativas no desempenho dos alunos do grupo experimental, } \\
\text { quando comparado aos estudantes do grupo de controle. }\end{array}$ \\
\hline $\begin{array}{c}\text { Guimarães E Sena } \\
{[2010]}\end{array}$ & $\begin{array}{c}\text { Uso do Laboratório de } \\
\text { Informática das Escolas }\end{array}$ & $\begin{array}{l}\text { A prática pedagógica, estabelecida no laboratório de informática, da maioria } \\
\text { dos professores está aquém do que deveria acontecer, pois não promove de } \\
\text { maneira significativa o processo de ensino aprendizagem. }\end{array}$ \\
\hline $\begin{array}{c}\text { Martins } \text { et al., } \\
\text { [2003] }\end{array}$ & $\begin{array}{c}\text { Simulações de Software } \\
\text { on-line }\end{array}$ & $\begin{array}{l}\text { Estudo realizado com alunos portugueses do ensino básico (14 - 16 anos) } \\
\text { que mostra as vantagens pedagógicas deste tipo de simulações. }\end{array}$ \\
\hline $\begin{array}{c}\text { Medeiros e } \\
\text { Medeiros [2002] }\end{array}$ & Animações e Simulações de \\
Veit e Teodoro & $\begin{array}{l}\text { A construção do conhecimento em um contexto amplo que englobe os } \\
\text { conteúdos e os processos de construção. }\end{array}$ \\
\hline [2002] & Modelagem com Software & $\begin{array}{l}\text { A exploração e a criação de múltiplas representações de fenômenos físicos e } \\
\text { de objetos matemáticos. }\end{array}$ \\
\hline $\begin{array}{c}\text { Wesendonk } \\
{[2015]}\end{array}$ & Softwares de Simulação & $\begin{array}{l}\text { Experimentações simuladas contribui para o uso desse recurso nas aulas de } \\
\text { Física. }\end{array}$ \\
\hline
\end{tabular}

\subsection{Ferramentas de Ensino Online Khan Academy}

A Khan Academy surgiu da iniciativa de ajudar as pessoas que estavam distantes geograficamente com a compreensão de conteúdos de matemática através de conteúdo multimídia. Neste contexto, foram surgindo novas demandas e estímulos para o desenvolvimento de novos mecanismos adaptados à dificuldade propiciada pela distância. Com isso, foi criado um programa de computador para acompanhamento de resolução de exercícios. Contudo, percebeu que o grande desafio realmente era o processo de aprendizado, e, para tanto, a gravação de vídeos e disponibilização para as pessoas foi a solução [Khan, 2019].

Os vídeos são uma solução, que atendem a várias necessidades, pois as pessoas podem parar e rever o conteúdo, ou mesmo assisti-lo no momento em que for mais conveniente. Além disso, facilita à conveniência dos professores, pois podem gravar os vídeos no momento em que tiverem disponibilidade e não precisam repetir a mesma explicação.

O funcionamento da plataforma é simples: o interessado acessa o site, cria uma conta e, a partir disso, tem acesso a todos os conteúdos da plataforma. Para iniciar a disciplina, o usuário realiza um pré teste para verificar seu nível de conhecimento e, de acordo com o resultado, a plataforma encaminha o usuário para atividades que estejam relacionadas a seu nível. Os avanços na disciplina ocorrem a medida que o aluno alcança a competência necessária, recebendo bonificações/medalhas a cada avanço de fase, possibilitando um aprendizado de forma lúdica e divertida, respeitando o ritmo e a 
condução do aprendizado do aluno. Além disso, o professor também pode ter acesso a todos os progressos do aluno e ao que ele tem desenvolvido na plataforma, desde que esteja cadastrado e tenha a turma do aluno sob sua administração na plataforma. Com isso, a plataforma possibilita ao professor acompanhar seus alunos, planejando suas aulas com uma visão ampliada do todo da turma, além de proporcionar uma visão individual de cada aluno.

\section{Materiais e Métodos}

Esta pesquisa tem finalidade descritiva e a abordagem quantitativa, pois houve o levantamento de dados sobre uso da tecnologia e a avaliação do uso da ferramenta nas unidades de análise, fazendo uso da técnica do estudo de multi-casos. Os estudos de caso são adequados para pesquisas que tem por objetivo uma investigação complexa onde é necessário ter uma visão do todo, caso deste trabalho [Gil, 2010].

O universo da pesquisa foram duas escolas estaduais do município de Francisco Beltrão - PR, com 22 turmas de Ensino Médio. Justifica-se a escolha desse universo devido aos pesquisadores estarem inseridos no contexto das escolas, o que possibilita ao pesquisador uma melhor observação, pois relatar um experiência que advenha de sua prática e de seu ambiente de trabalho possibilita criar espaços para produzir conhecimentos que favoreçam o aprofundamento teórico e prático. Além disso, foi realizada a captura dos dados de 343 sujeitos da pesquisa (alunos). Tais indivíduos são detentores das informações necessárias para realização da análise. Diante disso, a pesquisa se divide em duas etapas:

Etapa 1 - Estímulo e Uso da Ferramenta: os alunos foram direcionados ao Laboratório de Informática, onde acessaram a plataforma e criaram de login e senha. $\mathrm{Na}$ sequência os alunos foram orientados a entrar no ambiente da disciplina, para acessar a diversidade de conteúdos, sendo que o aluno pode explorar e realizar os exercícios de qualquer um dos materiais. Diante disso, as atividades foram orientadas conforme o conteúdo que estavam sendo discutidos em sala de aula e constante na Tabela 2.

Tabela 2. Conteúdos da Disciplina de Física

\begin{tabular}{|l|l|}
\hline \multicolumn{1}{|c|}{ Série/Ano } & \multicolumn{1}{c|}{ Conteúdo } \\
\hline $1^{\mathbf{o}}$ & Leis de Newton \\
\hline $2^{\mathbf{o}}$ & Termodinâmica - Calor Latente e Específico \\
\hline $3^{\mathrm{o}}$ & Eletricidade - Potencial Elétrico \\
\hline
\end{tabular}

Etapa 2 - Avaliação e Análise: Nesta etapa, ocorre a avaliação da utilização ferramenta educacional aplicada na disciplina de Física. Para coletar os dados foi utilizado um questionário composto por quarenta e cinco questões que tinham como foco a avaliação da integração da ferramenta e o ensino de Física. Quanto às respostas, optou-se pela utilização da escala Likert, devido a sua confiabilidade para mensuração de comportamento a partir de um ranking de opções de respostas: Concordo plenamente, concordo parcialmente, não concordo nem discordo, discordo parcialmente e discordo plenamente [Dalmoro e Vieira, 2013]. Após a coleta, os dados foram tabulados com a utilização de planilha eletrônica. Em seguida, realizou-se a análise dos dados a partir da literatura, sendo que para facilitar a análise e a discussão dos resultados referentes ao uso da plataforma, bem como a visualização e o entendimento, optou-se por agrupar as respostas em três categorias: (i) conforme: respostas positivas, ou seja, concordo plenamente ou concordo parcialmente; (ii) não conforme: respostas 
IX Congresso Brasileiro de Informática na Educação (CBIE 2020)

Anais do XXXI Simpósio Brasileiro de Informática na Educação (SBIE 2020)

negativas, discordo parcialmente ou discordo plenamente; e (iii) parcial: não concorda nem discorda.

\section{Resultados e Discussão}

Inicialmente, são evidenciados dados estatísticos da população e amostra. É possível observar na Tabela 3, informações como: idade, sexo e perfil de utilização da Internet.

Tabela 3 - Idade e Perfil de Utilização da Internet

\begin{tabular}{|l|c|c|c|}
\hline \multicolumn{1}{|c|}{ Características } & $\begin{array}{c}\text { Total } \\
(\mathbf{n = 3 4 3 ; ~ 1 0 0 \% )}\end{array}$ & $\begin{array}{c}\text { Feminino } \\
(\mathbf{n = 1 3 4 ; ~ 3 9 , 1 \% )}\end{array}$ & $\begin{array}{c}\text { Masculino } \\
(\mathbf{n = 2 0 9 ;} \mathbf{6 0 , 9 \% )}\end{array}$ \\
\hline Idade (média em anos) & $16 \pm 0,8$ & $15 \pm 0,9$ & $16 \pm 0,1$ \\
\hline Tipo de Utilização da Internet & & & \\
\hline Busca de conteúdos para o trabalho & $34,7 \%$ & $49,2 \%$ & $25,3 \%$ \\
\hline Contato com amigos e familiares & $2,9 \%$ & $5,9 \%$ & $0,9 \%$ \\
\hline Jogos & $15,2 \%$ & 0 & $24,8 \%$ \\
\hline Redes Sociais & $87,5 \%$ & $44,7 \%$ & $33,5 \%$ \\
\hline Ler Noticias & $6,1 \%$ & 0 & $10,1 \%$ \\
\hline Frequência de Acesso a Internet & & & $18,2 \%$ \\
\hline De 3 a 5 vezes por semana & $16,9 \%$ & $14,9 \%$ & $76,5 \%$ \\
\hline Diariamente & $78,1 \%$ & $80,6 \%$ & $3,8 \%$ \\
\hline Semanalmente & $3,8 \%$ & $3,7 \%$ & \\
\hline
\end{tabular}

Da amostra pesquisada, percebe-se que a média de idade é de 16 anos, com maioria predominante do sexo masculino (60,9\%). Além disso, $87,5 \%$ dos estudantes utilizam-se da Internet para acesso a redes sociais, sendo que o uso da Internet se dá diariamente pela maioria dos respondentes $(78,1 \%)$. Entretanto, percebe-se que existe um quantitativo mínimo de pessoas $(6,1 \%)$ que buscam ler notícias da internet e considerável que destinam o acesso à pesquisas de conteúdos relacionados ao seu trabalho ou estudo (34,7\%). Isso é indicador de que o perfil desta faixa etária de alunos acessa à internet para buscar conteúdo somente em redes sociais. Neste ponto, [Lorenzo, 2013] indica que as instituições de ensino têm encontrado aplicações úteis das redes sociais na educação e, atualmente, passaram a ser importantes ferramentas no processo de ensino e aprendizagem. Por meio das redes, é possível compartilhar informações sobre temas estudados ou propostos em sala de aula, assim como fortalecer o envolvimento dos alunos e professores, por meio de um novo canal de comunicação, tornando-se uma eficiente opção para a construção do relacionamento entre alunos e professores.

Com relação, ao uso da plataforma Khan Academy como ferramenta auxiliar na disciplina de Física, após a sequência de apresentação, aplicação e utilização da plataforma, e aplicação do questionário avaliativo de percepção, obtiveram-se os resultados apresentados na Tabela 4.

De acordo com os resultado da Tabela 4, observa-se que a aceitabilidade dos alunos, da plataforma utilizada é positiva ( $92,3 \%$ de conformidades). Isso evidencia que a utilização de ferramentas e plataformas computacionais na disciplina de Física pode vir a trazer resultados relevantes e positivos no processo ensino aprendizagem. Pode-se observar que os alunos têm uma opinião positiva em relação ao uso de alguma ferramenta computacional educacional e avaliaram a ferramenta como de fácil utilização. Isso vai ao encontro de [Gonçalves, 2005] [Guimarães e Sena, 2010] [Bozelli e Nardi 2012] [Batista et al., 2012] [Andrade, 2015], que preconizam que com a utilização das tecnologias é possível desenvolver ambientes de aprendizagem que tornam disponível ao aluno animações, simulações, vídeos entre outros recursos que são atrativos e de fácil utilização. 
IX Congresso Brasileiro de Informática na Educação (CBIE 2020)

Anais do XXXI Simpósio Brasileiro de Informática na Educação (SBIE 2020)

Tabela 4. Avaliação do uso da plataforma Khan Academy nas aulas de Física

\begin{tabular}{|l|c|c|c|}
\hline \multicolumn{1}{|c|}{ CRITÉRIO } & Conforme & Parcial & $\begin{array}{c}\text { Não } \\
\text { conforme }\end{array}$ \\
\hline Gostou da aula com o uso do software & $80,8 \%$ & $11 \%$ & $8,2 \%$ \\
\hline O software é de fácil compreensão e uso & $97,4 \%$ & $2,6 \%$ & $0 \%$ \\
\hline O software mantém interação constante ao usá-lo & $99 \%$ & $1 \%$ & $0 \%$ \\
\hline Permite fácil interação com os professores & $89,6 \%$ & $10,4 \%$ & $0 \%$ \\
\hline Permite ampliação do conhecimento além do conteúdo ministrado em sala & $98,5 \%$ & $1,5 \%$ & $0 \%$ \\
\hline Pode acessar ao mesmo tempo o conteúdo e pesquisas de internet & $95,5 \%$ & $4,5 \%$ & $0 \%$ \\
\hline Há acesso a ajudas, para encaminhar a respostas certas & $93,8 \%$ & $5 \%$ & $1,2 \%$ \\
\hline $\begin{array}{l}\text { O uso de ilustrações, animaçães e recursos sonoros desperta, mantém e reforça a atenção e a a } \\
\text { motivação }\end{array}$ & $90,5 \%$ & $9,5 \%$ & $0 \%$ \\
\hline Há integração do software com outros recursos ou materiais instrucionais & $89,6 \%$ & $7,2 \%$ & $3,2 \%$ \\
\hline Há apresentação parcial dos resultados & $95,8 \%$ & $4,2 \%$ & $0 \%$ \\
\hline Há apresentação dos resultados para saber a sua posição diante do conteúdo aprendido & $90,7 \%$ & $9,3 \%$ & $0 \%$ \\
\hline O vocabulário é adequado para compreender o conteúdo e o que está sendo pedido & $96,4 \%$ & $2,4 \%$ & $1,2 \%$ \\
\hline Há possibilidade de reconhecimento do raciocínio & $90,2 \%$ & $5,4 \%$ & $4,4 \%$ \\
\hline O software garantiu um ambiente de aprendizado mais rico & $96,4 \%$ & $3,6 \%$ & $0 \%$ \\
\hline
\end{tabular}

Além disso, para discutir a importância do uso de programas computacionais no ensino de física é preciso analisar as ferramentas utilizadas, da mesma forma que se analisam as demais, como livros didáticos, por exemplo. Assim, pode-se observar que o uso de ferramentas computacionais educacionais não é somente uma iniciativa bem recebida pelos alunos, como também pode ser um viés para motivá-los nos seus estudos, tanto dentro como fora dos limites da escola, neste caso, possibilitando uma ampliação da sala de aula, de forma a favorecer a construção do conhecimento, onde o professor exerce a função de mediador e tutor dos conteúdos [Medeiros e Medeiros, 2002] [Martins et al., 2003] [Monteiro et al., 2007].

A utilização das tecnologias da informação e comunicação no ambiente escolar contribuem para uma mudança de paradigmas, sobretudo, para o aumento da motivação em aprender. Se a tecnologia for utilizada de forma adequada, tem muito oferecer, a aprendizagem se tornará mais fácil e prazerosa, pois "as possibilidades de uso do computador como ferramenta educacional estão crescendo e os limites dessa expansão são desconhecidos" [Batista et al., 2012].

Observou-se também, que a utilização de recursos audiovisuais proporcionados pela ferramenta funcionou como fator motivacional para iniciar ou dar continuidade na realização das tarefas. Cita-se como exemplo, um filme ou um programa multimídia que têm um forte apelo emocional e, por isso, motivam a aprendizagem dos conteúdos apresentados pelo professor. Além disso, a quebra de ritmo provocada pela apresentação de um audiovisual ou utilização de uma plataforma ou recurso computacional é saudável, pois altera a rotina da sala de aula [Veit e Teodoro, 2002][Wesendonk, 2015]

Com relação a interação humano-ferramenta e aluno-professor que a ferramenta proporciona, percebe-se que os alunos indicam que o ambiente mantém interação constante, enquanto desenvolvem as atividades e proporciona uma maior interação com o professor, contribuindo conforme colocam [Bozelli e Nardi, 2012] [Wesendonk, 2015] para um melhor desempenho, além de trazer melhorias consideráveis para o processo de ensino-aprendizagem, tanto nas aulas teóricas, quanto nas aulas experimentais.

Quanto a integração da ferramenta com outros materiais instrucionais e com a internet, visualiza-se que a plataforma possibilita a integração de forma efetiva. Neste 
ponto, acrescenta-se que ao utilizar uma plataforma computacional, além do planejamento e adequação do professor, é preciso que a plataforma escolhida possibilite ao aluno fazer a interligação entre os demais materiais que são utilizados rotineiramente, além é claro, de propiciar que outras atividades como a pesquisa, possam ser desenvolvidas durante o momento de execução das tarefas [Guimarães e Sena, 2010] [Wesendonk, 2015].

Indo ao encontro da literatura [Martins et al., 2003] [Monteiro et al., 2007] [Guimarães e Sena, 2010] [Bozelli e Nardi, 2012] [Fiorio et al., 2014] [ Fiorio et al., 2019][ Chih-Ming, Ming-Chaun, Tze-Chun 2020] [Banerje, Olson, 2020] [Guo, 2020] [Wang et al, 2020] [Kettle 2020] os alunos colocam que a utilização da ferramenta permite uma busca maior pelo conhecimento, ou seja, a busca torna-se mais ativa e transcende as colocações do professor e das referências utilizadas por ele. Ainda, [Alvarez e Dal Sasso, 2011] evidenciaram que a aplicação dos objetos virtuais contribuem significativamente para o aumento do conhecimento constituindo uma promissora perspectiva para educação.

Com relação ao encaminhamento das respostas dos exercícios propostos na ferramenta, observa-se que a mesma disponibiliza uma forma de ajuda para envio das respostas e, também, proporciona o envio de respostas parciais e apresenta os resultados para que o aluno saiba do seu progresso. Com isso, é permitido que o professor acompanhe os progressos dos estudantes identificando dificuldades e limitações, propiciando que os planejamentos posteriores levem em consideração essas informações.

Com a visão de que a tecnologia possa estar ou não a serviço das pessoas, os professores podem ser críticos para contemplar em sua prática pedagógica o uso da informática, oferecendo esse recurso aos alunos. Os professores e os alunos podem utilizar as tecnologias da informação para estimular o acesso à informação e à pesquisa individual e coletiva, favorecendo o processo para aumentar a interação entre eles. Com o uso de ferramentas computacionais, ao longo do tempo, o aluno pode deixar de ser receptor de informações para ser responsável pela construção do seu conhecimento, pois por meio da internet é possível buscar e selecionar as informações significativas segundo o seu interesse. Cabe ao professor construir ambientes de aprendizagem desafiadores e direcionar para que a tecnologia ajude a promover o desenvolvimento cognitivo no aluno e o leve à construção do conhecimento [Moran et al., 2012]

Observa-se que o vocabulário utilizado pela plataforma apresentava-se adequado, isto é, as instruções apresentadas podiam ser facilmente compreendidas, pois tinham um vocabulário compatível com o perfil dos alunos. Essa avaliação, de acordo com Guimaraes e Sena [2010] e Wesendonk [2015], precisa ser realizada pelo professor durante o planejamento das aulas, para que não haja incompatibilidade entre as linguagens e, principalmente, que isso não desestimule o estudante na utilização da plataforma e, assim, possa vir a desequilibrar o processo ensino-aprendizagem.

Ao final, observou-se que o ambiente computacional proporciona um aprendizado mais rico, trazendo satisfação aos estudantes, pois propicia um ambiente e forma diferenciada de ensino, despertando o interesse dos alunos pelos conteúdos e auxiliando alguns no entendimento dos conceitos vistos em sala. Neste caso, um indicador que este trabalho está em consonância com Moran [2013], Bozelli e Nardi [2012] e Wesendonk [2015], visto que as ferramentas computacionais permitem pesquisar, simular situações, testar conhecimentos específicos, descobrir novos conceitos, lugares, ideias, avaliações e experiências. Com isso, o professor pode, por meio de uma metodologia inovadora, criar possibilidades de encontros presenciais e virtuais que levem o aluno a acessar as informações disponíveis em todo o universo da internet, motivando-o e sensibilizando-o sobre o valor da atividade que vai ser realizada e de sua importância nesse processo. A 
partir daí o aluno participa e torna-se responsável pela qualidade e escolha das informações coletadas, sendo o professor o mediador desse processo de aprendizagem.

Com isso, trabalhar o ensino de Física, uma disciplina considerada pelos alunos de difícil compreensão, requer algumas mudanças como: propostas curriculares que valorizem a construção e troca do conhecimento; uma estrutura equipada com mais recursos (laboratórios, televisão, computadores, softwares, dentre outros) e acima de tudo procurar novas soluções que auxiliem no processo de ensino e aprendizagem do aluno [Comicioli, 2013] [Posada et al., 2016] [Fiorio, et al., 2014] [Fiorio, et al., 2019].

\section{Conclusões}

Neste trabalho, utilizamos a ferramenta de ensino online Khan Academy, como auxiliar no processo de ensino-aprendizagem em conteúdo da disciplina de Física para o Ensino Médio em Escolas da rede pública de ensino da cidade de Francisco Beltrão - PR. Percebeu-se que a aplicação que a princípio pareceria complexa, se mostrou bastante eficiente, pois chamou a atenção do aluno e estimulou o desenvolvimento da lógica atrelada no ensino do conteúdo. A grande vantagem percebida na aplicação da ferramenta de ensino online no processo de educação, foi com relação a facilidade que os conteúdos interativos e multimídia possuem de prender a atenção do aluno, e proporcionar com isso, um melhor processo de aprendizagem.

Neste contexto, conseguimos observar que existem várias possibilidades de uso da informática no ensino da Física que possibilitam um enriquecimento do ensino. Neste ponto, ferramentas computacionais podem propiciar aos estudantes maiores habilidades no processo de construção e análise do conhecimento, partindo de conceitos mais gerais, para os mais específicos, gerando assim, uma aprendizagem mais significativa. Ressalta-se a importância de utilizarmos esse tipo de ferramenta de maneira a auxiliar o processo educativo, mas sabemos que o professor possui papel fundamental nesse processo como incentivador da utilização das tecnologias da informação no meio educacional. Percebe-se que através de estímulos de ferramentas computacionais que propiciem o ensino, o aluno pode ser levado a criar e construir com eficácia, o seu próprio conhecimento, não só na escola, mas no seu cotidiano, oportunizando lhe a ampliação do seu próprio conhecimento, como um ser político-social. Através da utilização da ferramenta online Khan Academy, os alunos mostraram mais motivação nas aulas, bem como, relataram que o software proporciona uma aprendizagem mais dinâmica e interativa.

Enfim, o cotidiano no âmbito escolar muitas vezes não permite que o professor tenha acesso a recursos tecnológicos, seja pela escassez do recurso seja pela dificuldade em manuseá-lo, para incrementar sua aula. Porém, com essa experiência dentro das escolas, pode-se perceber que repassar o conhecimento das áreas tecnológicas e incentivar seu uso pode trazer resultados esperados por qualquer docente: a participação, desenvolvimento do pensamento crítico e o aprendizado de seu aluno. Como trabalhos futuros, sugere-se ampliar a população de estudo, buscando fazer um comparativo tanto entre escolas públicas como privadas. Além disso, percebe-se a possibilidade da modelagem e desenvolvimento de um software, com paradigmas de gamificação, que possa ser utilizado nas disciplinas da área de exatas, como matemática, física e química.

\section{Referências}

Andrade, M. E (2016) "Simulação e modelagem computacional com o software Modellus: aplicações práticas para o ensino de física”, São Paulo: Ed. Liv. Física. 
IX Congresso Brasileiro de Informática na Educação (CBIE 2020)

Anais do XXXI Simpósio Brasileiro de Informática na Educação (SBIE 2020)

An, D. Y. , Silva, C. D. Ribeiro, D. M. G. Rocha, P. B. R. Maltinti, C. Nunes, V. B. and Fávero, R. (2013) "Digita-um Jogo Educativo de Apoio ao Processo de Alfabetização Infantil” In: Simpósio Brasileiro de Informática na Educação, vol. 24.

Alvarez, A.G, Dal Sasso, G.T.M (2011) "Aplicação de objeto virtual de aprendizagem, para avaliação simulada de dor aguda, em estudantes de enfermagem", In: Rev Latino Am Enferm. Vol. 19, nº 2, p. 29-37.

Araujo, I. S. Dorneles, P. F.T; Veit, E. A. (2006) "Simulação e Modelagem Computacional no Auxílio à Aprendizagem Significativa de Conceitos Básicos de Eletricidade: Parte 1: Circuitos elétricos simples" In: Revista Brasileira de Ensino de Física, São Paulo, Vol. 28, nº 4, p. 487-496.

Banerjee, H. \&. Olson, J. E (2020) What learning tools do students prefer? An assessment of undergraduate business courses, Journal of Education for Business,

Batista, E. J. S. (2015) "Utilizando o Scratch como ferramenta de apoio para desenvolver o raciocínio lógico das crianças do ensino básico de uma forma multidisciplinar" In: XXI Workshop de Informática na Escola - WIE.

Batista, S., Behar, P., \& Passerino, L. (2012) "M-learnMat: Modelo Pedagógico para Atividades de M-learning em Matemática”, In: Simpósio Brasileiro de Informática na Educação - SBIE, 23(1).

Bozelli, F.C.; Nardi, R. (2012) "Interações discursivas e o uso de analogias no ensino de física" In: Investigações em Ensino de Ciências, v.17, n.1, 2012, p. 81-107.

Chih-Ming Chen, Ming-Chaun Li, Tze-Chun Chen, (2020) A web-based collaborative reading annotation system with gamification mechanisms to improve reading performance, Computers \& Education, Volume 144.

Comicioli, L. B. (2013) "Uso da plataforma Moodle como ferramenta de apoio para a criação de uma monitoria virtual de física", Trabalho de Conclusão de Curso. Universidade Federal de Santa Catarina.

Dalmoro, M. Vieira, K. M. (2013) "Dilemas na construção de escalas tipo likert: o número de itens e a disposição influenciam nos resultados?”, In: Revista gestão organizacional, vol. 6 edição especial.

Fiorio, R., Esperandim, R., Silva, F., Varela, P., Leite, M., \& Reinaldo, F. (2014) "Uma experiência prática da inserção da robótica e seus benefícios como ferramenta educativa em escolas públicas" In: Simpósio Brasileiro de Informática na Educação.

Fiorio, R., Varela, P., Albonico, M., \& Semler, J. (2019) "Linguisticun: Uma Ferramenta de Auxílio ao Ensino da Língua Portuguesa e à Linguística Computacional" In: Simpósio Brasileiro de Informática na Educação - SBIE.

Gonçalves, L.J (2005) "Uso de Animações Visando a Aprendizagem Significativa de Física Térmica no Ensino Médio”. Dissertação. Univ. Fed. do Rio Grande do Sul.

Gil, A. C. (2010) "Como elaborar projetos de pesquisa", 5. ed. São Paulo: Atlas.

Guimarães, T. M.; Sena, R. M. (2010) "Educação e tecnologia: práticas pedagógicas desenvolvidas nos laboratórios de informática das escolas públicas de cáceres e região", In: Workshop de Informática na Escola.

Guo, S. (2020) "Synchronous versus asynchronous online teaching of physics during the COVID-19 pandemic". Physics Education, volume 55, nº 5 
IX Congresso Brasileiro de Informática na Educação (CBIE 2020)

Anais do XXXI Simpósio Brasileiro de Informática na Educação (SBIE 2020)

Kettle, M.(2020) "How videos are used in secondary school physics teaching".Physics Education, 55.

Khan Academy. (2019) "Plataforma web Khan Academy", disponivel em < https://pt.khanacademy.org/about> Acesso em 14/08/2019

Lorenzo, E. M. (2013) "A Utilização das Redes Sociais na Educação: A Importância das Redes Sociais na Educação". 3 ed. São Paulo: Clube de Autores.

Luz , J. W. P., Fonseca, L. C. C.. (2013) "EduConnect: uma ferramenta de apoio à aprendizagem colaborativa para dispositivos móveis em redes MANET", In: Anais do Simpósio Brasileiro de Informática na Educação, vol. 24, no. 1.

Martins, A. J.; Fiolhais, C.; Paiva, J. (2003) "Simulações on-line no ensino de Física e da Química". Revista Brasileira de Informática na Educação, v.11, n. 2.

Medeiros, A.; Medeiros, C. F. (2002) "Possibilidades e Limitações das Simulações Computacionais no Ensino da Física", In: Revista Brasileira de Ensino de Física.

Monteiro, M. A. A.; Santos, D. A.; Teixeira, O. P. B. (2007) "Caracterizando a autoria no discurso em sala de aula”, In: Invest. em Ensino de Ciências, v.12, n.2, p.205-225.

Mortimer, E. ; Scott, P. (2002) "Atividade discursiva nas salas de aula de ciências: uma ferramenta sociocultural para analisar e planejar o ensino", In: Investigações em ensino de ciências, v. 7, n.2. Porto Alegre.

Moran, J. M; Masetto, M. T; Behrens, M. A. (2012) "Novas tecnologias e mediação pedagógica", Campinas (SP): Papirus.

Moran, J. M. (2013) “Novas tecnologias e mediação pedagógica”, Papirus Editora.

Nascimento, J. O. do; Neide, I. G; Gonzatti, S. E. M. (2015) "Modelagem e simulação computacional no ensino de Física: Uma proposta de estudo de caso com o PROEJA" In: XXI Simpósio Nacional de Ensino de Física, v. 1. p. 1-8.

Neto, S., Santos, H., de Souza, A., \& dos Santos, W. (2013) "Jogos Educacionais como Ferramenta de Auxílio em Sala de Aula" In: Workshop de Informática na Escola.

Posada, J. E. G.; Buchdid, S. B.; Baranauskas, M .C. C. (2016) "A informática na educação: o que revelam os trabalhos publicados no Brasil", In: Revista Brasileira de Informática na Educação, Volume 24, Número 1.

Torezani, C., Chagas, L., \& Tavares, O. (2013) "NewProg-um ambiente online para crianças aprenderem programação de computadores", In: Workshop de Informática na Escola, vol. 1, no. 1.

Trentin, M., Pérez, C., \& Teixeira, A. (2013) "A robótica livre no auxílio da aprendizagem do movimento retilíneo", In: Workshop de Informática na Escola.

Veit, E.A.; Teodoro, V.D. (2002) "Modelagem no Ensino/Aprendizagem de Física e os Novos Parâmetros Curriculares Para o Ensino Médio", In: Revista Brasileira de Ensino de Física, São Paulo, v. 24, n. 2, p. 87-96.

Wang Y. et al (2020) "Research on the small private online course (SPOC) teaching model incorporating the just-in-time teaching (JiTT) method based on mobile Internet for learning college physics".European Journal of Physics Vol 41, No 2 .

Wesendonk, F. S. (2015) "O uso da experimentação como recurso didático no desenvolvimento do trabalho de professores de Física do Ensino Médio", Dissertação de Mestrado em Educação para a Ciência. Faculdade de Ciências, UNESP, Bauru. 